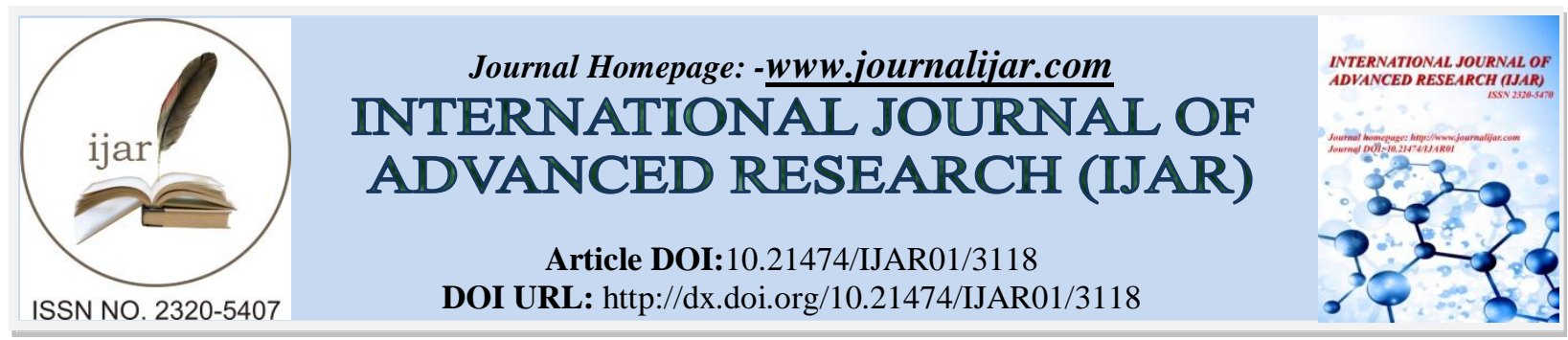

RESEARCH ARTICLE

\title{
EVALUATION OF LIPID PEROXIDATION AND ANTIOXIDANT ENZYME ACTIVITIES IN TYPE 2 DIABETICPALESTINIAN PATIENTS FROM THE GAZA STRIP.
}

${ }^{*}$ Ali Abd El-Aal ${ }^{1}$, Mahmoud Sirdah ${ }^{2}$, Eman A. Abd El-Ghffar ${ }^{1}$ and Asmaa S. Abughali ${ }^{1}$

1. Department of Zoology, Faculty of Science, Ain Shams University, Cairo, Egypt.

2. Department of Zoology, Faculty of Science, Al-AzharUniversity,Gaza,Palestine.

\section{Manuscript Info}

Manuscript History

Received: 11 December 2016

Final Accepted: 05 January 2017

Published: February 2017

Key words:-

Antioxidant, Oxidative stress, Lipid peroxidation, type 2 diabetes.

\section{Abstract}

Background and Objective: Diabetes mellitus is a group of metabolic disorders associated with increased oxidative stress and free radical production that play important roles in diabetic pathogenesis and complications. The present study was aimed to evaluate lipid peroxidation and antioxidant enzyme activities in patients with type 2 diabetes in comparison with normal healthy individuals.

Material and Method: Lipid peroxidation and antioxidant enzymes: Malondialdehyde (MDA), glutathione peroxidase (GSH-Px), glutathione reductase (GR), glutathione- $\mathrm{S}$-transferase (GST), reduced glutathione (GSH) and lipid profiles were determined in 40 males of type 2 diabetic patients, in addition to 10 males of healthy controls matched for age and BMI. Descriptive, statistical comparisons, and correlations were performed using the SPSS program, significance was considered when $P$ value $<0.05$

Results:The MDA, GR, and GSTconcentrations were significantly increased in type 2 diabetic patients compared with the healthy controls group. While significant reduction in the activities of GSH and GSHPx were reported in type 2 diabetic patients compared with the healthy controls group. Significant positive correlations between oxidative stress status (MDA and GST) and lipid profiles (especially total cholesterol, LDL-C, triglyceride and VLDL-C) were found in type 2 diabetic patients.

Conclusion:Our study revealed an increase lipid peroxidation coupled with decrease antioxidant enzymes in type 2 diabeticPalestinian patients from the Gaza Strip.

Copy Right, IJAR, 2017,. All rights reserved.

\section{Introduction:-}

Diabetes mellitusis a group of metabolic disorders characterized by hyperglycemia (Lin and sun, 2010) resulting from insulin resistance (IR) and fall of functional pancreatic $\beta$ cells. Chronic hyperglycemia causes serious complications for diabetic patients, such as damage, dysfunction, and failure of various organs, especially the eyes, kidneys, nerves, heart, and blood vessels (Expert Committee on the Diagnosis and Classification of Diabetes Mellitus, 1997, 2003). According to the World Health Organization (WHO), more than 220 million persons worldwide had diabetes; $90 \%$ of them are diagnosed with type 2 diabetes (WHO, 2009). In 2005, 1.1 million people worldwide died from diabetes and the WHO estimates that the number of deaths may double between 2005 and 
2030 (WHO, 2009). The reasons for this global rise are the growth of aged population, increasing trends towards obesity, unhealthy diet, and sedentary lifestyle (Bagust et al., 2001; Cowieet al., 2008). This condition requires medical treatment and a number of lifestyle changes.

Diabetes mellitus is associated closely with increased oxidative stress and free radical production (BonnefontRousselot $\boldsymbol{e t}$ al., 2000). Oxidative stress reflects an imbalance between the formation of free radical oxygen and antioxidant defense system in the body (Rahimi et al., 2005). Oxidative stress plays an important role in the pathogenesis of diabetes and its complications (Johansen et al., 2005; Rahimiet al., 2005). In the diabetic condition, oxidative stress, through the production of reactive oxygen species (ROS), impairs glucose uptake in muscle and fat (Rudich et al., 1998; Maddux et al., 2001) and decreases insulin secretion from pancreatic $\beta$ cells (Matsuoka et al., 1997).

Several diabetic complications are associated with overproduction of ROS and accumulation of lipid peroxidation products (Palanduz et al., 2001), which is potentially harmful because it's uncontrolled, the self-enhancing process causes disruption of membranes, lipids, and other cell components.

There is not much data available about the relationship between oxidative stress and diabetes in Palestinian type 2 diabetic patients at Gaza strip. Therefore, the aim of the present study is to evaluate oxidative stress by measuring lipid peroxidation and antioxidant enzymes in patients with type 2 diabetes as compared to healthy controls, also to determine the correlations between the pro-oxidant (lipid status) and antioxidant parameters in studied subjects.

\section{Materials and Methods:-}

Subjects:The current study was conducted on 40males patients with type 2 diabetes. The patients were chosen from those attending the United Nations Relief and Works Agency for Palestine Refugees in the Near East (UNRWA) health centers in Gaza Strip. Clinical examination was done for all patients to exclude any diabetic complication such as neurologic, cardiac, kidney, and eye complications. All patients were on oral hypoglycemic agents Metformin.Ten healthy subjects (10 males) matching the average age and socioeconomic status were selected randomly as a control group. The healthy subjects were chosen randomly from those working at UNRWA health centers. Clinical examination was also done for all healthy subjects to exclude any health problem that may they suffer from. None of the patients or control subjects reported any intake of dietary supplements such as vitamins or minerals, at least in the last year before launching the study.

Measurements: Weight,height, waist circumference (WC), waist hip ratio (WHR) and blood pressure were measured for each subject then the body mass index was calculated as following: BMI = Body weight $(\mathrm{Kg}) /$ height $\left(\mathrm{m}^{2}\right)$ (Bray, 1987).

Blood samples and biochemical parameters: Blood samples were collected from each subject after an overnight fasting (at least 8-12 hours). Glycosylated hemoglobin (HbAlc) was measured by a direct enzymatic method (Goldstein et al., 2004). Serum MDA was measured by thiobarbituric acid assay (Satoh, 1978). Serum GSH, GR, GST and GSH-Px activities were measured by the method ofBeutleret al., (1963), Goldberg et al., (1983),Habig et al., (1974) andPaglia et al., (1967) respectively, by using Biodiagnostic kit.Fasting blood glucose level, urea, creatinine, uric acid, alanine aminotransferase (ALAT) and aspartate amino transferase (ASAT), triglycerides, total cholesterol and high density lipoprotein cholesterol (HDL-C) levels were measured by using Diasys kit.

Low density lipoprotein cholesterol (LDL-C) was estimated by the equation of Friedewaldet al., (1972). LDL-C = [Total cholesterol - (Triglyceride/5 + HDL-C)].

\section{Statistical Analysis:-}

Statistical Package of social science (SPSS) version 22 was used for analysis of data. Data was summarized as mean \pm standard deviation (SD) and compared between type 2 diabetic patients and healthy controls subjects. Pearson's correlations were also performed to define correlations of individual parameters. All statistical tests were two-tailed. $P$ values $\leq 0.05$ were considered statistically significant. 


\section{Results:-}

The descriptive characteristics of the type 2 diabetic patients and healthy control subjects are shown in Table 1 . The type 2 diabetic group significantly differed from the healthy control group in fasting blood glucose level ( $88.15 \pm$ 3.31 vs. $158.82 \pm 5.07, P<0.05)$ and $\mathrm{HbA1c} \%(5.53 \pm 0.13 v s .8 .43 \pm 0.214, P<0.05)$.

Table 1:- Comparison of descriptive characteristics and glycemic status between healthy control and type 2 diabetic subjects.

\begin{tabular}{|l|l|l|l|}
\hline Variables & $\begin{array}{l}\text { Healthy control } \\
\text { N }(10 \mathrm{M}) \\
\text { Mean } \pm \text { SD }\end{array}$ & $\begin{array}{l}\text { Type 2 diabetic patients } \\
\text { N }(40 \mathrm{M}) \\
\text { Mean } \pm \text { SD }\end{array}$ & $P$-value \\
\hline Age (years) & $50.10 \pm 2.16$ & $51.02 \pm .86$ & $>0.05$ \\
\hline W.C (cm) & $113.70 \pm 4.18$ & $106.82 \pm 1.194$ & $>0.05$ \\
\hline WHR & $0.98 \pm 0.03$ & $0.99 \pm 0.01$ & $>0.05$ \\
\hline BMI (kg/m $\left.\mathbf{m}^{2}\right)$ & $32.79 \pm 1.42$ & $30.96 \pm 0.69$ & $>0.05$ \\
\hline Systolic & $117.00 \pm 2.13$ & $120.19 \pm 1.100$ & $>0.05$ \\
\hline Diastolic & $77.00 \pm 2.13$ & $78.59 \pm 1.382$ & $>0.05$ \\
\hline FBG $(\mathbf{m g} / \mathbf{d L})$ & $88.15 \pm 3.31$ & $158.82 \pm 5.07$ & $<0.05$ \\
\hline HbA1c $(\%)$ & $5.53 \pm 0.13$ & $8.43 \pm 0.214$ & $<0.05$ \\
\hline
\end{tabular}

BMI, body mass index; FBS, fasting blood glucose; HbA1c, glycosylated hemoglobin.WHR, waist hip ratio; $P<$ 0.05 is significant.

The lipid profiles of the type 2 diabetic patients and healthy control subjects were shown in Table 2 . The diabetic subjects had significantly increase $(P<0.05)$ in serum triglyceride, $(138.45 \pm 14.66 v s .237 .08 \pm 9.74)$, VLDL-C levels $(27.69 \pm 2.93 v s .47 .33 \pm 1.95)$ andHDL-C $(45.30 \pm 1.37 v s .39 .37 \pm 1.13)$ compared with healthy control subjects.

Table 2:- Lipid profile in healthy control and type 2 diabetic subjects.

\begin{tabular}{|l|l|l|l|}
\hline Variables & $\begin{array}{l}\text { Healthy control } \\
\text { N }(10 \mathrm{M}) \\
\text { Mean } \pm \text { SD }\end{array}$ & $\begin{array}{l}\text { Type 2 diabetic patients } \\
\text { N }(40 \mathrm{M}) \\
\text { Mean } \pm \text { SD }\end{array}$ & $P$-value \\
\hline TC $(\mathbf{m g} / \mathbf{d l})$ & $194.22 \pm 6.67$ & $213.57 \pm 4.72$ & $>0.05$ \\
\hline TG $(\mathbf{m g} / \mathbf{d l})$ & $138.45 \pm 14.66$ & $237.08 \pm 9.74$ & $<0.001$ \\
\hline HDL-C (mg/ dl) & $45.30 \pm 1.37$ & $39.37 \pm 1.13$ & $<0.05$ \\
\hline LDL-C (mg/dl) & $121.23 \pm 5.41$ & $126.79 \pm 4.52$ & $>0.05$ \\
\hline VLDL-C (mg/dl) & $27.69 \pm 2.93$ & $47.33 \pm 1.95$ & $<0.001$ \\
\hline
\end{tabular}

TC, total cholesterol; TG, triglycerides; HDL-c, high density lipoprotein; LDL-c, low density lipoprotein; VLDL-c, very low density lipoprotein. $P<0.05$ is significant. $P<0.001$ is highly significant.

The concentrations of MDA, GR, GST were found to be highly increased in type 2 diabetic patients, $(P<0.05)(2.56$ $\pm 0.20 v s .4 .30 \pm 0.21),(13.73 \pm 0.33 v s .21 .08 \pm 0.55)$, $(351.28 \pm 17.63 v s .508 .44 \pm 11.756)$ respectively, in contrastGSH-PxandGSH activity were significantly decreased in type 2 diabetic patients, $(P<0.05)$ as compared to healthy control subjects $(738.81 \pm 26.38 v s .514 .32 \pm 15.83),(41.00 \pm 1.41 v s .26 .93 \pm 0.846)$ respectivelyas shown in Table-3.

Table 3:-Oxidant and antioxidant parameters in healthy control and type 2 diabetic subjects.

\begin{tabular}{|l|l|l|l|}
\hline Variables & Healthy control & Type 2 diabetic patients & $P$-value \\
& N $(10 \mathrm{M})$ & $\mathrm{N}(40 \mathrm{M})$ & \\
& Mean \pm SD & $4.30 \pm 0.21$ & \\
\hline MDA (nmoL/mL) & $2.56 \pm 0.20$ & $21.08 \pm 0.55$ & $<0.05$ \\
\hline GR (U/ L) & $13.73 \pm 0.33$ & $508.44 \pm 11.756$ & $<0.05$ \\
\hline GST (U/L) & $351.28 \pm 17.63$ & $514.32 \pm 15.83$ & $<0.05$ \\
\hline GSH-Px(mU/ mL) & $738.81 \pm 26.38$ & $26.93 \pm 0.846$ & $<0.05$ \\
\hline GSH(mg/dL) & $41.00 \pm 1.41$ & $<0.05$ \\
\hline
\end{tabular}


GSH-Px, glutathione peroxidase;GR, glutathione reductase;GSH, reduced glutathione; GST, glutathione -Stransferase;MDA, malondialdehyde.

There is no significant difference in liver and kidney functions parametersin type 2 diabetic patientswhen compared with healthy control subjects. Table-4.

Table 4:-Liver and kidney functions parameters in healthy control and type 2 diabetic subjects.

\begin{tabular}{|l|l|l|l|}
\hline Variables & $\begin{array}{l}\text { Healthy control } \\
\mathrm{N}(10 \mathrm{M}) \\
\text { Mean } \pm \text { SD }\end{array}$ & $\begin{array}{l}\text { Type 2 diabetic patients } \\
\text { N }(40 \mathrm{M}) \\
\text { Mean } \pm \text { SD }\end{array}$ & \\
\hline ALAT $(\mathbf{m g} / \mathbf{d l})$ & $20.48 \pm 1.32$ & $23.52 \pm 1.29$ & \\
\hline ASAT $(\mathbf{m g} / \mathbf{d l})$ & $19.40 \pm 0.85$ & $18.80 \pm 0.82$ & $>0.05$ \\
\hline Urea $(\mathbf{m g} / \mathbf{d l})$ & $27.94 \pm 0.78$ & $27.28 \pm 0.56$ & $>0.05$ \\
\hline Uric acid(mg/dl) & $5.45 \pm 0.28$ & $4.88 \pm 0.18$ & $>0.05$ \\
\hline Creatinine (mg/dl) & $0.81 \pm 0.05$ & $0.78 \pm 0.019$ & $>0.05$ \\
\hline
\end{tabular}

ALAT, alanine aminotransferase; ASAT; aspartate aminotransferase.

\section{Discussion:-}

In the present study, the patients with type 2 diabetes had shown elevation of HbA1c comparing to their agedmatched healthy individuals. It has been reported that various proteins, hemoglobin and LDL, undergo nonenzymatic glycation in diabetes (Klein., 1995). The rate of glycation is proportional to the concentration of blood glucose (Sheelaet al., 1992). In addition, HbA1c has been found to be increased over a long period of time in diabetes (Bunn $\boldsymbol{e t} \boldsymbol{a l}$., 1978). Free radical increases proportionally with increased glycation rate (Gupta $\boldsymbol{e t}$ al., 1997). So, the measurement of HbA1c is very sensitive index for glycemic control (Jain et al., 1989).

In the current work, we found that patients with type 2 diabetes were presented with low HDL-C and high triglyceride levels. This result is compatible with the previous studies (Howard, 1987; Taskinen., 1992; Yoshino et al., 1996). The insufficient amounts of anti-atherogenic and antioxidative effects due to the low level of HDL-C, is a key feature for oxidative stress status (Hansel $\boldsymbol{e t}$ al., 2004). The reduced HDL-C level is often accompanied with high level of triglyceride (Lamarcheet al., 1996), which is in agreement with the present study. In type 2 diabetes, the increased secretion of apolipoprotein B (apoB) as a result of fatty acid synthesis in the liver (Duvillard et al., 2000; Krauss et al., 2004), a protein identified as a key component of the VLDL which induced an increase in plasma level of triglyceride and reduce level of HDL-C. Moreover, the elevation of free fatty acid and glucose in type 2 diabetes may decrease the activity of lipoprotein lipase, a pivotal enzyme in the removal of these lipoproteins from the circulation, and control the triglyceride-rich lipoproteins and HDL-C particles (Kastelein et al., 1999).

The present study showed significant increases in MDA, GR, GST, and significant decreases in GSH and GSH-Px levels in patients with type 2 diabetes as compared with the control, which is an indication of marked oxidative stress. The increase of oxidative stress in diabetes mellitus was explained by several mechanisms. These mechanisms fall into two general categories first; Increased production of ROS, second; decreased antioxidant defenses. In diabetes, glucose auto oxidation and glycation products, non-enzymatic protein glycosylation, and changes in antioxidant defense systems can increase production of ROS (Baynes 1991; Inouye et al., 1999; Bonnefont-Rousselot et al., 2000; Courderot-Masuyeret al., 2000; West, 2000). Increased production of ROS as well as reduced antioxidant defense mechanisms have been suggested to play a role in type 1 and type 2 diabetic patients (Mahboobet al., 2001).

A significant increase in MDA was observed in patients with type 2 diabetes as compared with the healthy individuals. MDA, the end product of lipid peroxidation and acts as a marker of balance between pro-oxidant and antioxidant. This balance is a disturbance in diabetic patients. As a result, there is a high level of MDA present in the serum of patients with type 2 diabetes. This result is in agreement with the finding of (Griesmacheret al., 1995; Beaudeuxet al., 1995; Pasaoglu et al., 2004; Ozdemir et al., 2005). Hyperglycemia may increase of ROS and lipid peroxidation production that is dependent in the redox potential of non-enzymatic antioxidant (glutathione) and decreased enzymatic antioxidant defense system.

The decrease in GSH-Px activity and the increase in GR activity were significant in patients with the type 2 diabetes as compared to the healthy individuals. These results are similar with the results of previous studies (Kumawat $\boldsymbol{e t}$ 
al., 2005). The low activity of GSH-Px could be directly explained by the low content of GSH found in patients with the type 2 diabetes since GSH is a substrate and cofactor of GSH-Px. Enzyme inactivation could also contribute to the low GSH-Px activity. GSH-Px is a relatively stable enzyme, but it may be inactivated under conditions of severe oxidative stress. Inactivation of this enzyme may occur through glycation governed by prevailing glucose concentration (Rahbani-Nobar $\boldsymbol{e t}$ al., 1999). The increased activity of GR may be a compensatory response to oxidative stress. The changes in GSH-Px and GR activities found in this study may be considered as an adaptation of antioxidant defense against the increased production of ROS.

GSH dependent enzyme activities, such as GSSH-Px, $\gamma$-glutamyltranspeptidase, and GST were changed in diabetes (Ballatori et al., 2009). The results showed that patients with the type 2 diabetes had lower GSH concentrations in erythrocytes (RBCs) than observed in the healthy individuals. This result is similar to the finding of Livingstone $\boldsymbol{e t}$ al., (2007). The present results showed that GST activity was increased significantly in patients with type 2 diabetes than in the healthy individuals. In RBCs, decreased GSH as well as increased serum total GST levels may be due to a compensatory mechanism of the antioxidants to defense the oxidative stress in diabetic conditions.

Positive correlation between MDA, total cholesterol and LDL-C, as well as positive correlation between GST, triglyceride and VLDL-C were found in patients with the type 2 diabetes. Positive correlations between GSH-Px and LDL-C in healthy individuals could indicate possible association between high lipid concentrations leading to accelerated lipid peroxidation and potentially increased the reduction of the organic hydroperoxides as a consequence of increased activity of GSH-Px. No such correlation was found in patients with the type 2 diabetes, while these were other significant correlations between GSH-Px and triglyceride in the healthy individuals.

\section{Conclusions:-}

It was concluded that the Palestinian patients with the type 2 diabetes are presented with a significant increase in lipid peroxidation coupled to a significant decrease in the antioxidant mechanism. The study suggests the evaluation of antioxidant levels as a useful marker in the prevention of the diabetic complications.

\section{References:-}

1. Bagust A, Hopkinson PK, Maier W, Currie CJ. An economic model of the long-term health care burden of type 2 diabetes.Diabetologia, 2001; 44: 2140-2155.

2. Ballatori N, Krance SM, Notenboom S, Shi S, Tieu K, Hammond CL. Glutathione dysregulation and the etiology and progression of human diseases, 2009 ;390(3):191-214.

3. Baynes JW. Role of oxidative stress in development of complication in diabetes.Diabetes, 1991;40: 405 — 412.

4. Beaudeux JL, Guillausseau PJ, Peynet J, Flourie F, Assayag M, Tielmans D, Warnet A, Rousselet F. Enhanced susceptibility of low-density lipoprotein to in vitro oxidation in type 1 and type 2 diabetic patients. ClinChimActa, 1995; 239: 131-41.

5. Beutler E, Duron O, Kelly MB. J. Lab Clin. Med, 1963; 61: 882.

6. Bonnefont-Rousselot D, Bastard JP, Jaudon MC, Delattre J. Consequences of the diabetic status on the oxidant/antioxidant balance.Diabetes Metabolism, 2000; $26: 163-176$.

7. Bray GA. Overweight is risking factor: definition, classification, prevalence, and risk. Ann. N. Y. Acad. Sci, 1987; 499: 14-28.

8. Bunn HG, Gabby KH, Gallop PM. The glycosylation of hemoglobin: relevance to diabetes mellitus. Science, 1978; 200: 21-27.

9. Courderot-Masuyer C., Lahet J. J., Verges B., Brun J. M., Rochette L. Ascorbylfree radical release in diabetic patients. Cell. Mol. Biol, 2000; $46: 1397-1401$.

10. Cowie CC, Rust KF, Byrd-Holt DD, Eberhadt MS, Flegal KM, Engelgau MM, Saydah SH, Williams DE, Geiss LS, Gregg EW.Prevalence of Diabetes and Impaired Fasting Glucose in Adults in the U.S. Population. Diabetes Care, 2006; 29:1263-1268.

11. Duvillard L, Pont F, Florentin E, Galland-Jos C,Gambert P, Verges B. Metabolic abnormalities ofapolipoprotein B-containing lipoproteins in noninsulin-dependent diabetes: a stable isotope kineticstudy. Eur J Clin Invest, 2000; 30: 685-94.

12. ExpertCommittee on the Diagnosis and Classification of Diabetes Mellitus.Report of the Expert Committee on the Diagnosis and Classification of Diabetes Mellitus.Diabetes Care, 1997; 20: 1183-1197. Available at: http://dx.doi.org/10.2337/diacare.20.7.1183 
13. The American Diabetes Association.Report of the Expert Committee on the Diagnosis and Classification of Diabetes Mellitus. Diabetes Care, 1997;20:1183-1197. Available at: http://dx.doi.org/10.2337/diacare.20.7.1183

14. The American Diabetes Association.Report of the Expert Committee on the Diagnosis and Classification of Diabetes Mellitus.Diabetes Care, 2003; 26: s5-s20. http://dx.doi.org/10.2337/diacare.26.2007.S5

15. Friedewald W, Levy R, Fredrickson D. Estimation of the concentration of low density lipoprotein in plasma, without use of the preparative ultra-centrifuge.Clin Chem,1972; 18:499-502.

16. Goldberg DM. \& Spooner RJ in Methods of Enzymatic Analysis (Bergmeyen, H.V. Ed.)VerlogChemie, Deerfield beach, 1983; 3: $258-265$.

17. Goldstein DE, Little RA, Lorenz JI, Malone D, Nathan CM. Petreson, Sacks DB.Tests of glycemia in diabetes.Diabetes care, $2004 ; 27(7) 1761-1773$.

18. Griesmacher A, Kindhauser M, Andert SE, Schreiner W, Toma C, Knoebl P, Pietschmann P, PragerR, SchnackCh ,Schemthaner G, Mueller. Enhanced serum levels of thiobarbituric-acid-reactive substances in diabetes mellitus. Am J Med,1995; 98: 469-75.

19. Gupta BL, Nehal M, Baquer NZ: Effect of experimental diabetes on the activities of hexokinase, glucose-6phosphate dehydrogenase and catecholamines in rat erythrocytes of different ages. Indian J ExpBiol,1997; 35: 792-795.

20. Habig W and Pabst M Jakoby WJ .Biol .Chem, $1974 ; 249: 7130$ - 7139.

21. Hansel B, Giral P, Nobecourt E, Chantepie S, Bruckert E, Chapman MJ, KontushA.Metabolic syndrome is associated with elevated oxidative stress and dysfunctional dense high-density lipoprotein particles displaying impaired antioxidative activity. J ClinEndocrinolMetab, 2004; 89: 4963-71.

22. Howard BV. Lipoprotein metabolism in diabetes mellitus.J Lipid Res, 1987; 28: 613-28.

23. Inouye M, Moi T, Sumino K. Link between glycation and lipoxidation in red blood cells in diabetes. Clin.Chim.Acta, 1999; $285: 35-44$.

24. Jain SK, Robert M, John D, John JH: Erythrocyte membrane lipid peroxidation and glycosylated hemoglobin in diabetes. Diabetes, 1989; 38: 1539-1543.

25. Johansen JS, Harris AK, Rychly DJ, Ergul A. Oxidative stress and the use of antioxidants in diabetes: linking basic science to clinical practice. CardiovascDiabetol,2005;4:5.

26. Kastelein JJ, Ordovas JM, Wittekoek ME, Pimstone SN, Wilson WF, Gagne SE, Larson MG, Schaefer EJ, Boer JM, Gerdes C, Hayden MR. Two common mutations (D9N, N291S) in lipoprotein lipase: a cumulative analysis of their influence on plasma lipids and lipoproteins in men and women. Clin Genet,1999; 56: 297-305.

27. Klein R. Hyperglycemia and microvascular and macrovascular disease in diabetes.Diabetes Care, 199518 : $258-268$.

28. Krauss RM, Siri PW. Dyslipidemia in type 2 diabetes.Med Clin North Am, 2004; 88: 897-909.

29. Kumawat M, Singh N, and Singh S. Status of antioxidant enzymes and lipid peroxidation in type 2 diabetes mellitus with neuropathy. Annals of Neurosciences, 2005; 12: 49-52.

30. Lamarche B, Despres JP, Moorjani S, Cantin B, Dagenais GR, Lupien PJ. Triglycerides and HDL-cholesterol as risk factors for ischemic heart disease.Results from the Quebec cardiovascular study.Atherosclerosis, 1996; 119: 235-45.

31. Lin Y, Sun Z. Current views on type 2 diabetes. J Endocrinol, 2010; 204:1-11.

32. Livingstone C. and Davis J. Review: targeting therapeutics against glutathione depletion in diabetes and its complications. British Journal of Diabetes and Vascular Disease, 2007; 7: 258-265.

33. Maddux BA, See W, Lawrence JC, Goldfine AL, Goldfine D, Evans JL. Protection against oxidative stressinduced insulin resistance in rat L6 muscle cells by micromolar concentrations of $\alpha$-lipoic acid. Diabetes, 2001; 50:404-410.

34. Mahboob M, Shireen K, Atkinson A, Khan A. Lipid peroxidation and antioxidant enzyme activity in different organs of mice exposed to low level of mercury. J Environ Sci. Health, B.2001; 36: 687-97.

35. Matsuoka T, Kajimoto Y, Watada H, KanetoH, Kishimoto M, Umayahara Y, FujitaniY, Kamada T, Kawamori $\mathrm{R}$, Yamasaki Y. Glycation-dependent, reactive oxygen species-mediated suppression of the insulin gene promoter activity in HIT cells. J. Clin. Invest, 1997; 99:144-150.

36. Ozdemir G, Ozden M, Maral H, Kuskay S, CetilapP,Turkun I. Malondialdehyde, Glutathione peroxidase andhomocysteine level in type 2 diabetic patients with and without microalbuminuria. Ann ClinBiochem, 2005; 42:99-104.

37. Paglia DE and Valentine WNJ.Lab. Clin. Med,1967;70: 158 - 169.

38. Palanduz S, Ademoğlu E, Gökkuşu C, Tamer S. Plasma antioxidants and type 2 DM. Res. Commun. MolPatholPharmacol,2001; 109: 309-18. 
39. Pasaoglu H, Sancak B, Neslihan B. Lipid peroxidationand resistance to oxidation in patients with type 2 diabetesmellitus. Tohoku J Exp Med,2004; 203: 211-8.

40. Rahbani-Nobar M. E, Rahimi-Pour A, and RahbaniNobar M. Total antioxidant capacity, superoxide dismutase and glutathione peroxidase in diabetic patients. Medical Journal of Islamic Academy of Sciences, 1999; 12: 109-114.

41. Rahimi R, Nikfar S, Larijani B, Abdollahi M. A review on the role of antioxidants in the management of diabetes and its complications.Biomed Pharmacother, 2005;59:365-73.

42. Rudich A, Tirosh A, PotashnikR, Hemi R, Kanety H, Bashan N. Prolonged oxidative stress impairs insulininduced GLUT4 translocation in 3T3-L1 adipocytes. Diabetes, 1998; 47:1562-1569.

43. Satoh K , Serum lipid peroxide in cerebrovascular disorders determined by a new colorimetric method. ClinicaChimicaActa,1978; 90, 37.

44. Sheela GL, Augusti KT: Antidiabetic effect of S-allyl cysteine sulphoxide isolated from garlic Allium sativum L. Indian J ExpBiol, 1992; 30: 523-526.

45. Taskinen MR. Quantitative and qualitative 66 lipoprotein abnormalities in diabetes mellitus.Diabetes, 1992; 41(Suppl 2): 12-7.

46. West IC. Radicals and oxidative stress in diabetes.Diabet Med, 2000; 17:171-80.

47. World Health Organization Fact Sheet \#312: Diabetes Atlas, 4th edition, International Diabetes Federation, 2009. 1. 1. 1. 2. Available at: (http://www.who.int/mediacentre/factsheets/fs312/en/). Accessed month November 2008.

48. Diabetes is a chronic disease that occurs when the pancreas ....Diabetes Fact Sheet, WHO, November 2008. (http://www.who.int/mediacentre/factsheets/fs312/en/). Diabetes Atlas, 4th edition, International Diabetes Federation,2009. 1. 1. 1.2.

49. Yoshino G, Hirano T, Kazumi T. Dyslipidemia in diabetes mellitus. Diabetes ResClinPract, 1996; 33: 1-14. 